\title{
Distribution of Atmospheric Aerosol over the South China Sea
}

\author{
Shih-Jen Huang and Chen-Chih Lin \\ Department of Marine Environmental Informatics, National Taiwan Ocean University, Keelung, Taiwan \\ Correspondence should be addressed to Shih-Jen Huang; huangsj@mail.ntou.edu.tw \\ Received 15 May 2015; Revised 27 June 2015; Accepted 5 July 2015 \\ Academic Editor: Yuriy Kuleshov
}

Copyright ( $) 2015$ S.-J. Huang and C.-C. Lin. This is an open access article distributed under the Creative Commons Attribution License, which permits unrestricted use, distribution, and reproduction in any medium, provided the original work is properly cited.

The satellite-derived aerosol optical depth (AOD) data is used to investigate the distribution of aerosol over the South China Sea (SCS). High correlation coefficients are found between in situ AERONET data and satellite AOD measurements around the SCS with the highest coefficient of 0.9 on the Dongsha Island (i.e., Pratas Island). The empirical orthogonal function (EOF) analysis of AOD over the SCS shows that high AOD is always found around offshore areas of China, Indochina, Sumatra, and Borneo. Besides, spring is the major season of occurring coarse aerosol particles (AOT_C) but fine aerosol particles (AOT_F) occur yearly. The biomass burning is found in Indochina during March and April, and so it is in Sumatra and Borneo from August to October. The results also show that the AOT_F are higher during El Niño events, but higher AOT_C are found in La Niña years.

\section{Introduction}

The South China Sea (SCS) is not only the largest marginal sea of the Pacific in Southeast Asia but also abundant with marine resources. It covers an ocean area from the equator to $22^{\circ} \mathrm{N}$ and from $100^{\circ} \mathrm{E}$ to $121^{\circ} \mathrm{E}$ with a bathymetry deeper than $3000 \mathrm{~m}$ in the center and the north. It is also a major sea route connecting the Pacific Ocean to the Indian Ocean (Figure 1). The SCS, located within the East Asian monsoon region [1-4], confronts the prevailing northeaster carrying dust mixed with anthropogenic aerosols during the winter monsoon season from November to April. In the summer monsoon season from June to September, the smoke particles associated with biomass burning in Borneo and Sumatra are transported to the southern SCS [5].

Over the SCS, most of the aerosols come from Mainland China, Indochina Peninsula, and Luzon Island. Besides, the other origin of aerosols is the biomass burning from Sumatra and Borneo in Indonesia from August to October [6]. A vast amount of aerosol, attributed to varied emissions (e.g., dust, anthropogenic, and biomass burning) from the Asian continent, has widely impacted on the ecosystem [7]. On March 19-21, 2010, a significant Asian dust storm affected large areas from the Gobi deserts to the West Pacific Ocean and southern China [8]. The airborne dust over the Central Asia can be identified by analyzing the satellite data due to the features of coarse and fine particles [9]. Wang et al. [10] measured the Asian dust and found that it can be further transported and sunk to the northern SCS during the springtime. Reid et al. [11] found that large aerosol events that happened in SCS are almost always associated with biomass burning. Indochina fire smoke is transported out over the Pacific Ocean and beyond during the winter monsoon period. The biomassburning aerosols were transported over the northern and eastern Southeast Asia [12]. Atwood et al. [13] showed that the El Niño event enhanced tropical burning. The seasonal winds at $850 \mathrm{hpa}$ transport the burning smoke from source regions (Maritime Continent) to the southwest of Singapore during the summer monsoon. Wang et al. [14] showed that the dry conditions associated with the El Niño event cause the largest regional biomass burning outbreak. The smoke was widely spread over the $5^{\circ} \mathrm{S}-5^{\circ} \mathrm{N}$ zone during the seasonal monsoonal transition period.

From previous studies above-mentioned, the aerosol variations over the SCS may be affected by monsoon and large scale atmospheric circulation. Therefore, to more understand the changes of spatial distribution and time series of aerosol over the SCS, the satellite base aerosol optical depth (AOD) data are analyzed thoroughly. 
TABLE 1: The mean of Aeronet AOD, root-mean-square-error (RMSE), and correlation coefficient (R) between monthly MODIS AOD and Aeronet AOD $500 \mathrm{~nm}$.

\begin{tabular}{lcccr}
\hline Aeronet St. & Location & Data period & Mean & RMSE \\
\hline Dongsha & $\left(116.729^{\circ} \mathrm{E}, 20.699^{\circ} \mathrm{N}\right)$ & $2009 / 09 \sim 2010 / 05$ & 0.286 & 0.078 \\
Mukdahan & $\left(104.676^{\circ} \mathrm{E}, 16.607^{\circ} \mathrm{N}\right)$ & $2003 / 11 \sim 2009 / 12$ & 0.360 & 0.157 \\
Pimai & $\left(102.564^{\circ} \mathrm{E}, 15.182^{\circ} \mathrm{N}\right)$ & $2003 / 02 \sim 2008 / 04$ & 0.355 & 0.116 \\
Hong Kong & $\left(114.180^{\circ} \mathrm{E}, 22.303^{\circ} \mathrm{N}\right)$ & $2005 / 11 \sim 2010 / 01$ & 0.528 & 0.153 \\
Bac Lieu & $\left(105.730^{\circ} \mathrm{E}, 9.280^{\circ} \mathrm{N}\right)$ & $2006 / 05 \sim 2009 / 02$ & 0.218 & 0.815 \\
Singapore & $\left(103.780^{\circ} \mathrm{E}, 1.298^{\circ} \mathrm{N}\right)$ & $2006 / 11 \sim 2010 / 05$ & 0.338 & 0.70 \\
\hline
\end{tabular}

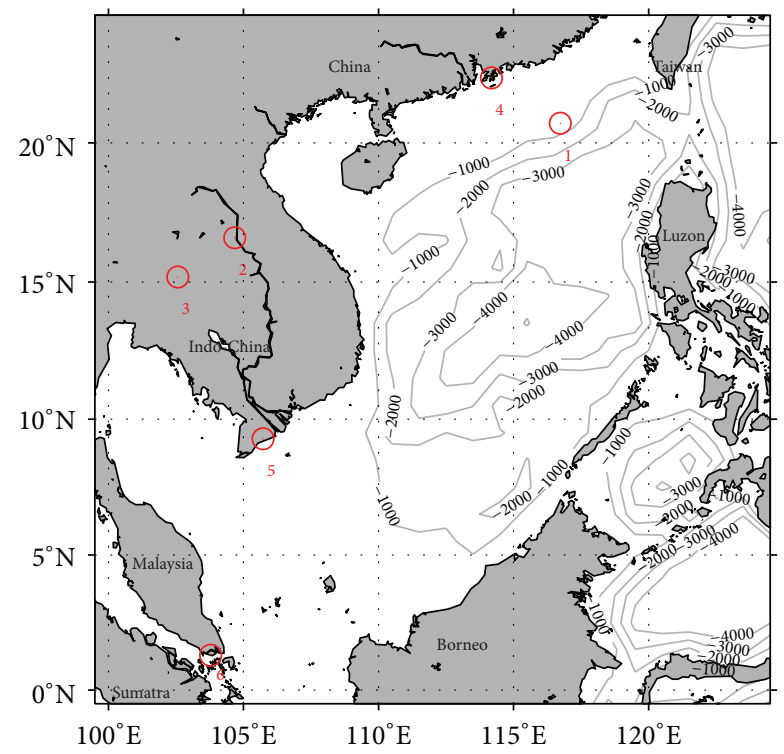

FIGURE 1: A map of SCS with isobaths. The circle represents Aeronet observation station, 1: Dongsha, 2: Mukdahan, 3: Pimai, 4: Hong Kong, 5: Bac Lieu, and 6: Singapore.

\section{Data and Methodology}

The AOD and fine mode fragment (FMF) at $500 \mathrm{~nm}$, proved by the National Aeronautics and Space Administration (NASA) Terra Moderate Resolution Imaging Spectroradiometer (MODIS) Level 3 satellite data from January 2001 to December 2012, are used in this study. The MODIS AOT data are masked when there are clouds. Therefore, no AOT value can be used during overcast days. Those data are then monthly averaged and the spatial resolution is $1^{\circ}$ latitude by $1^{\circ}$ longitude. The study area is located from the equator to $25^{\circ} \mathrm{N}$ and from $100^{\circ} \mathrm{E}$ to $125^{\circ} \mathrm{E}$ (Figure 1). Besides, the monthly in situ data from Aeronet observation stations around the SCS is also used in this study. To examine the relationship between MODIS AOD data and in situ Aeronet measurements, the correlation coefficient $(R)$ and root mean square error (RMSE) at each station are computed and presented in Table 1. Except Singapore and Bac Lieu of Vietnam stations, the stations have a higher correlation coefficient (larger than 0.7). The values of RMSE between MODIS AOD and Aeronet AOD at each station are smaller than the mean of those of Aeronet AOD implying that it can be used for the study of analyzing temporal and spatial variations of aerosol over the SCS. The AOD data are further divided into coarse mode aerosol (AOT_C) and fine mode aerosol (AOT_F) by FMF data as

$$
\begin{aligned}
& \text { AOT_F }=\text { AOD } \times \text { FMF }, \\
& \text { AOT_C }=A O D \times(1-F M F) .
\end{aligned}
$$

In order to analyze the spatial and temporal variations of aerosol, the empirical orthogonal function (EOF) and the fast Fourier transform (FFT) analyses are used. The error of EOF analysis, $e$, is estimated by the method of North et al. [15] as

$$
e=\lambda_{k} \sqrt{\frac{2}{N}}
$$

where $\lambda_{k}$ is the eigenvalues of covariance matrix at the $k$ th mode and $N$ is the degree of freedom.

It is known that the activities of El Niño and La Niña may affect the atmospheric and oceanic environments; their effects are taken into account in this study. The Oceanic Niño Index (ONI) constructed with the SST anomalies in the Niño 3.4 region $\left(5^{\circ} \mathrm{N}-5^{\circ} \mathrm{S}, 120^{\circ} \mathrm{W}-170^{\circ} \mathrm{W}\right)$ is used as the indicator in judging whether El Niño or La Niña phenomena are present. If the ONI value is larger than 0.5 , it is categorized as an onset of El Niño. If the value is smaller than -0.5 , it is classified as the time of La Niña events. It is deemed to be normal year if the value is between -0.5 and 0.5 .

\section{Results and Discussion}

3.1. Coarse Mode Aerosol Variation. The EOF analysis of AOT_C data has been performed. The contributions of eigenvalues and typical errors of first five modes are illustrated in Table 2. The errors of the EOF mode 4 and mode 5 overlap each other. Therefore, only the first three EOF modes with the cumulative variance over than $84 \%$ are discussed as follows.

The EOF mode 1 (EOF1) of the AOT_C is shown in Figure 2. Both the spatial distribution and the temporal amplitude are negative, which cause the result of positive sum. The higher negative value represents the higher AOT_C. Figure 2(a) shows a larger amount of AOT_C occurring in the coastal area of southern China and the Indochina Peninsula. On the temporal distribution of Figure 2(b), no periodic signal is found. In TEOF1 (Figure 2(b)), the larger amplitude appears in March or April normally, but not in every year. For example, in March 2006, April 2009, and 
TABLE 2: The contribution of eigenvalue at each EOF mode of AOT_C.

\begin{tabular}{lcc}
\hline EOF mode & $\begin{array}{c}\text { Contributing to variance } \\
\text { (typical errors) }(\%)\end{array}$ & $\begin{array}{c}\text { Cumulative } \\
\text { variance }(\%)\end{array}$ \\
\hline 1 & $79.42(69.17 \sim 89.67)$ & 79.42 \\
2 & $3.82(3.33 \sim 4.31)$ & 82.24 \\
3 & $1.97(1.71 \sim 2.22)$ & 84.21 \\
4 & $1.05(0.91 \sim 1.18)$ & 85.26 \\
5 & $0.94(0.82 \sim 1.06)$ & 86.20 \\
\hline
\end{tabular}

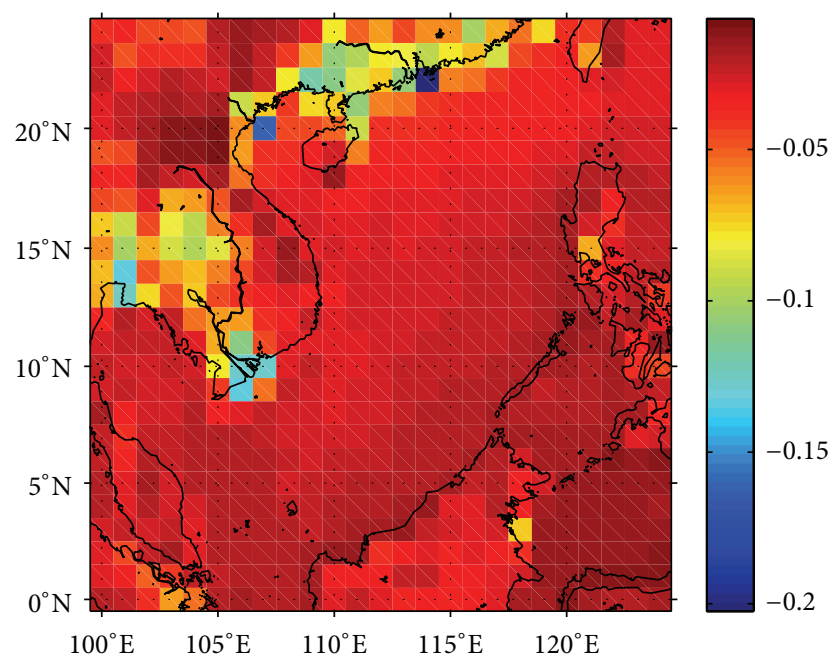

(a) AOT_C EOF $1(79.4 \%)$

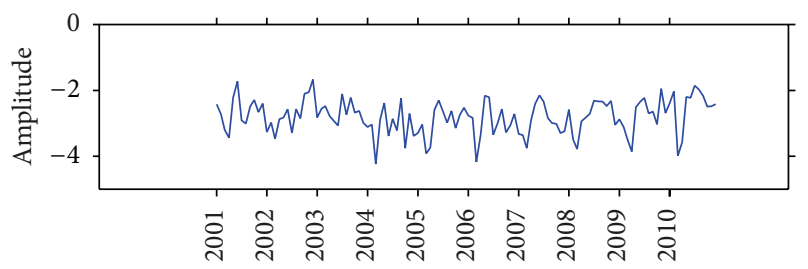

(b) AOT_CEOF $1(79.4 \%)$

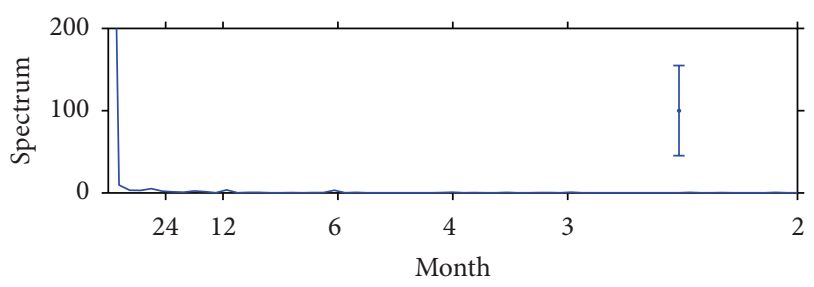

(c) AOT_C EOF 1 FFT

Figure 2: (a) The spatial distribution, (b) its corresponding timevarying amplitude for the vector EOF analysis mode 1 of the AOT_C in SCS during 2001/1-2010/12, and (c) the spectrum of (b) with FFT. The line segment represents the $95 \%$ confidence interval.

March 2010, the higher value of AOT_C was also obtained at Hong Kong AERONET station. Correspondingly, according to the studies of Tsay et al. [7] and Wang et al. [10], the Asia dust storms usually rage in spring, and the dust would be transported far to the SCS. This means that EOF1 displays

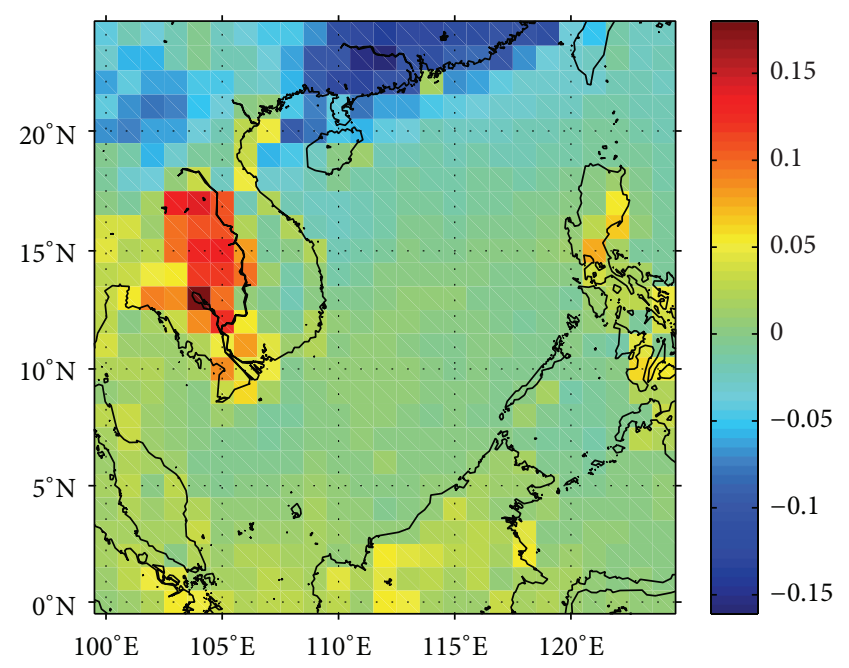

(a) AOT_C EOF $2(3.8 \%)$

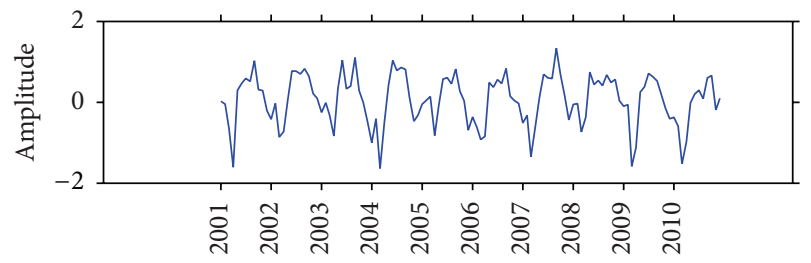

(b) AOT_C EOF 2 (3.8\%)

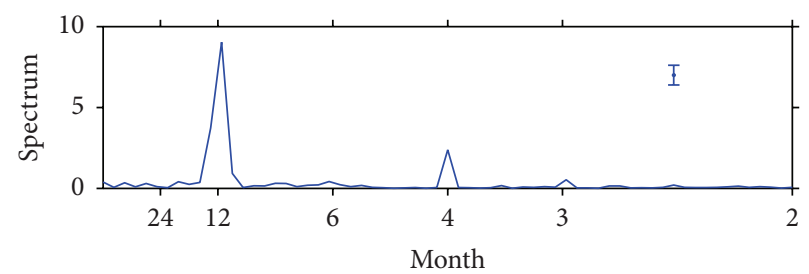

(c) AOT_C EOF 2 FFT

FIgURE 3: The same as Figure 2 but EOF mode 2 of AOT_C.

the random effect of whether accidental wildfires, sandstorm, or agricultural land development.

The result of EOF mode 2 (EOF2) of the AOT_C is shown in Figure 3. The spatial distribution in the Indochina Peninsula appears to have a positive value, but it is negative in southern China (Figure 3(a)). Meanwhile, the amplitude is positive from May to October with a maximum in September, while the negative amplitude appears from November to next April with a peak in January (Figure 3(b)). In other words, the AOT_C value in the Indochina Peninsula is higher than the average from May to October. Similarly, in southern China, the AOT_C value keeps higher during November and next April, and the maximum negative value appears in March.

The spatial distribution of EOF mode 3 (EOF3) displays that the positive value expands from the northwestern Indochina to its southeastern regions and the negative value is located in southern China (Figure 4(a)). The time series of EOF3 shows the positive value of amplitude from March to July, but the negative one from October to next February (Figure 4(b)). The spectrum analysis shows that the variation 


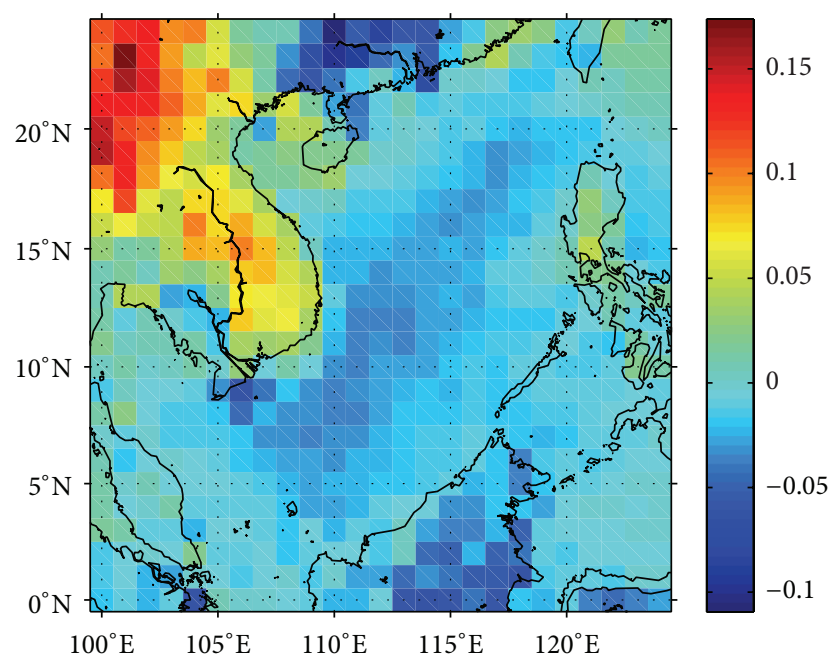

(a) AOT_C EOF 3 (1.9\%)

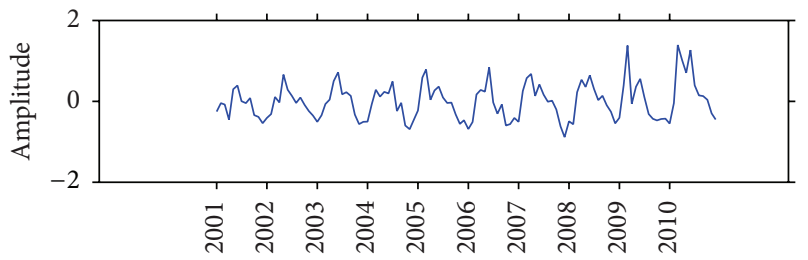

(b) AOT_C EOF 3 (1.9\%)

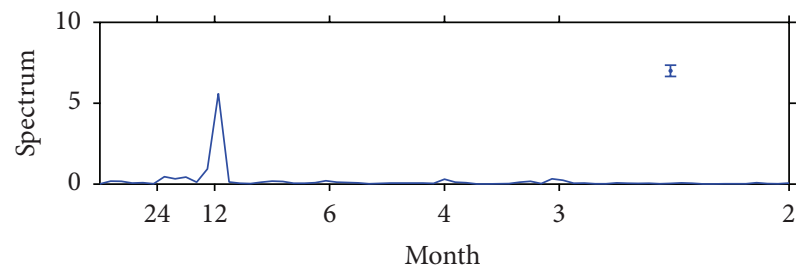

(c) AOT_C EOF 3 FFT

FIgUre 4: The same as Figure 2 but EOF mode 3 of AOT_C.

is yearly, but there is less energy than mode 1 and mode 2. As the result of mode 3, in the Indochina Peninsula, the AOT_C keeps higher during March and July. Figures 3(c) and 4(c) show the annual cycle regularly. Meanwhile, the coarse aerosol might erupt with the monsoon.

Consequently, there is a coincidence between the occurrence of high-value AOT_C and the high-value AOD observed at Aeronet observatories. The result indicates that the coarse aerosol particles mainly come from China and the Indochina Peninsula and occur annually. It corresponds to the previous studies $[7,8,10]$.

3.2. Fine Mode Aerosol Variation. Through the EOF analysis, the first five modes of AOT_F data are dealt with through the typical error analysis and are shown in Table 3, which contains the contribution of eigenvalues and typical errors of each EOF mode of AOT_F. The fifth mode and the sixth one overlap each other in typical error range, and the fourth mode only accounts for the variance amount of $2.19 \%$ where only the first three modes are discussed.
TABLE 3: The contribution of eigenvalue at each EOF mode of AOT_F.

\begin{tabular}{lcc}
\hline EOF mode & $\begin{array}{c}\text { Contributing to variance } \\
\text { (typical errors) }(\%)\end{array}$ & $\begin{array}{c}\text { Cumulative } \\
\text { variance }(\%)\end{array}$ \\
\hline 1 & $70.4(61.32 \sim 79.49)$ & 70.40 \\
2 & $11.90(10.37 \sim 13.44)$ & 82.30 \\
3 & $3.11(2.71 \sim 3.51)$ & 85.41 \\
4 & $2.19(1.90 \sim 2.47)$ & 87.60 \\
5 & $1.43(1.24 \sim 1.61)$ & 89.03 \\
6 & $1.15(1.00 \sim 1.29)$ & 90.18 \\
\hline
\end{tabular}

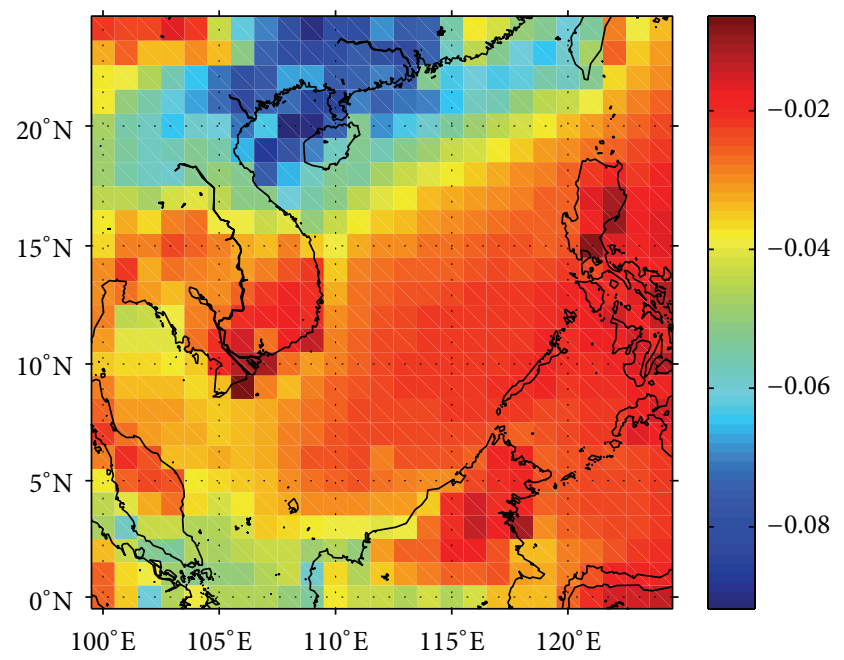

(a) AOT_F EOF 1 (70.4\%)

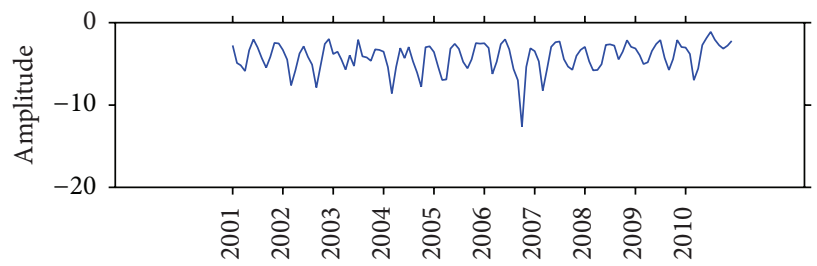

(b) AOT_F EOF $1(70.4 \%)$

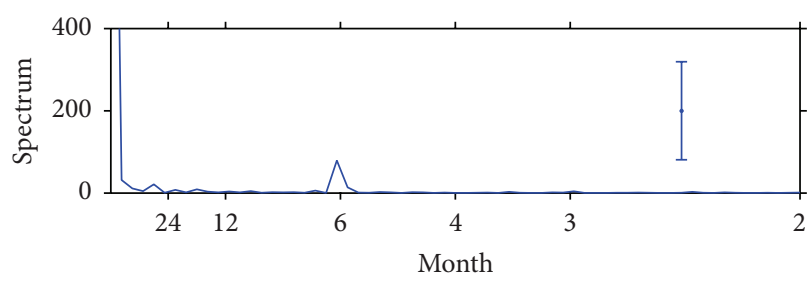

(c) AOT_F EOF 1 FFT

FIGURE 5: (a) The spatial distribution, (b) its corresponding timevarying amplitude for the vector EOF analysis mode 1 of the AOT_F in SCS during 2001/1-2010/12, and (c) the spectrum of (b) with FFT. The line segment represents the $95 \%$ confidence interval.

EOF1 of AOT_F shows that the largest variation area is in southern China, followed by Sumatra and Borneo in Indonesia (Figure 5(a)). The temporal amplitudes show two larger time phases from March to April and from August to October (Figure 5(b)). Meanwhile, the high-value fine aerosol particles were observed both at Aeronet observatories 


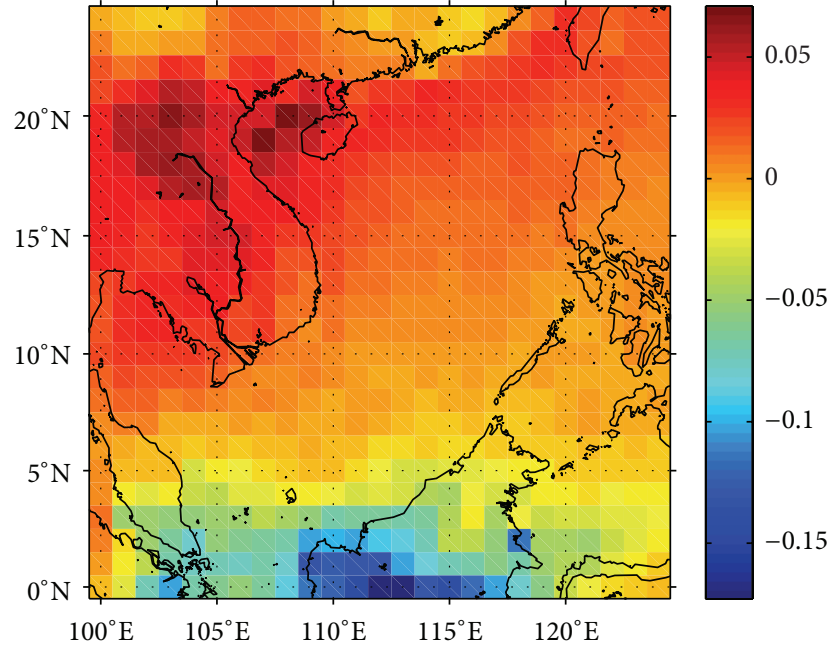

(a) AOT_F EOF 2 (11.9\%)

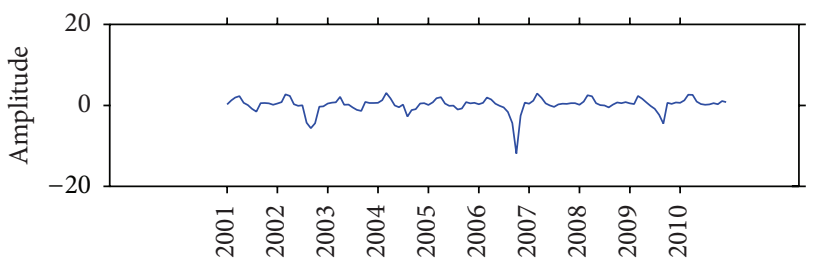

(b) AOT_F EOF 2 (11.9\%)

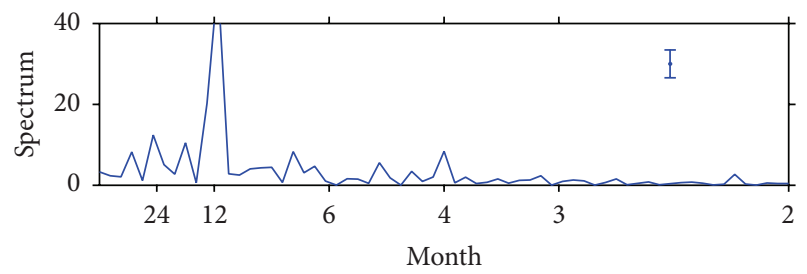

(c) AOT_F EOF 2 FFT

FIgUre 6: The same as Figure 5 but EOF mode 2 of AOT_F.

of Hong Kong and Bac Lieu. The two peaks appear every year probably due to the time different biomass burnings of these two regions.

Figure 6(a) shows the spatial distribution of EOF2 of AOT_F. The positive variation is in the Indochina Peninsula, while it is negative in Borneo. From the time series of amplitude (Figure 6(b)), the positive amplitude appears from November to next May, but the negative value is found during June and September. Therefore, the higher value of AOT_F is found in the Indochina Peninsula during March and April, and it also appears in Borneo and Sumatra during August and October. Two larger temporal amplitudes showed in October 2006 and September 2009. During these two months, the high value of fine aerosol particles was also found at the observatories of Hong Kong, Thailand, Dongsha, and Singapore. The spectrum analysis shows that the variation is an annual cycle which indicates that the fine aerosol particles are occurring in the abovementioned areas every year.

Figure 7(a) shows the spatial distribution of EOF3 of AOT_F. Positive values are in the Indochina Peninsula,

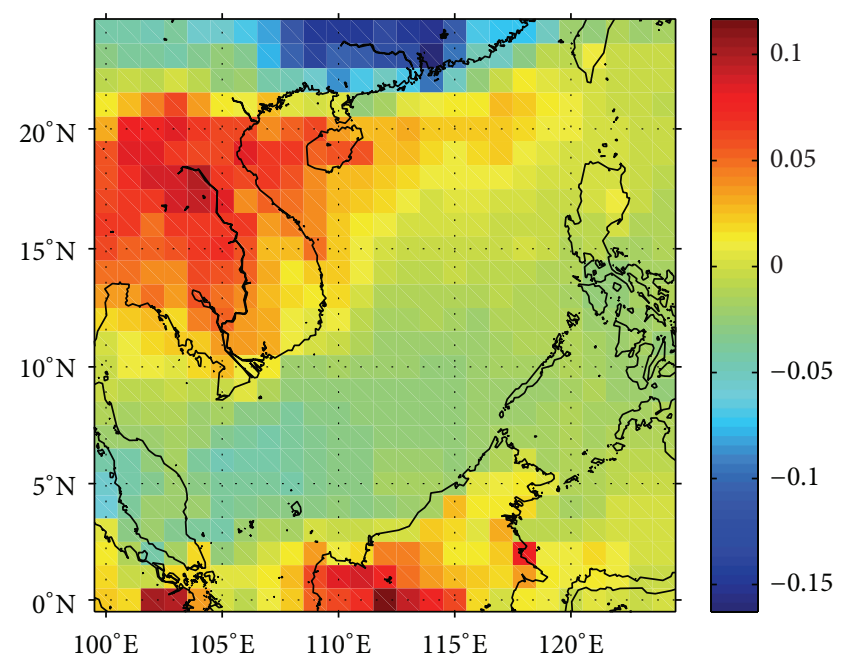

(a) AOT_F EOF 3 (3.1\%)

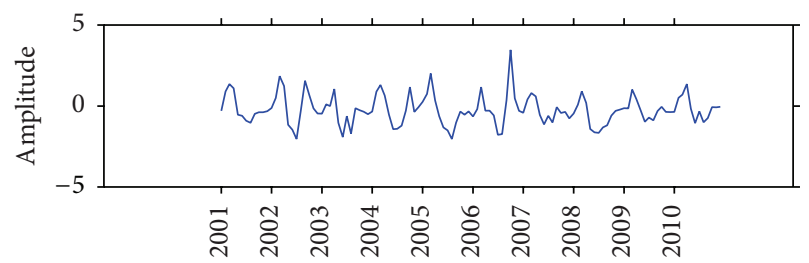

(b) AOT_F EOF 3 (3.1\%)

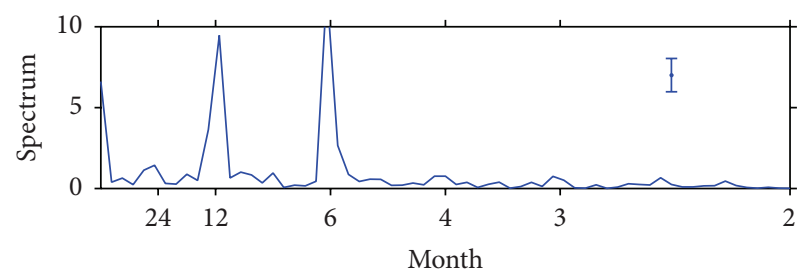

(c) AOT_F EOF 3 FFT

FIgURE 7: The same as Figure 5 but EOF mode 3 of AOT_F.

the Luzon Strait, and Borneo, but negative values are only found in China. Combining the time series of amplitude (Figure 7(b)) indicates that more AOT_F are found in the Indochina and Borneo from February to April and in China from May to August. The amplitude distribution also shows that the maximum positive amplitude is larger during El Niño period. Figure $7(\mathrm{c})$ shows the significant peak at annual cycle and semiannual cycle. It corresponds to the results of Lu et al. [16].

Previous results indicate that the higher AOT_F corresponds to the biomass burning around the SCS from March to April and from August to October [5, 6], which are similar to the result of this study. Moreover, the AOT is also affected by El Niño and La Niña events. Figure 8 shows the average AOT_C and AOT_F over the SCS during the normal, El Niño, and La Niña periods. The average AOT_C is smaller in El Niño period. On the contrary, the average AOT_F is larger in the El Niño events. Because during El Niño periods, the trade winds reverse direction, blowing from west to east (Asia towards Peru), the source of coarse particle (AOT_C) blown 


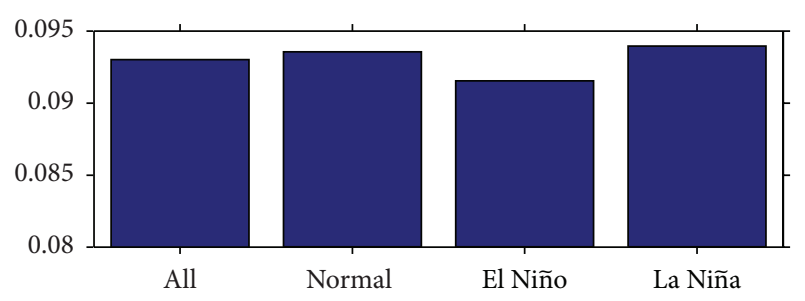

(a) Mean of AOT_C

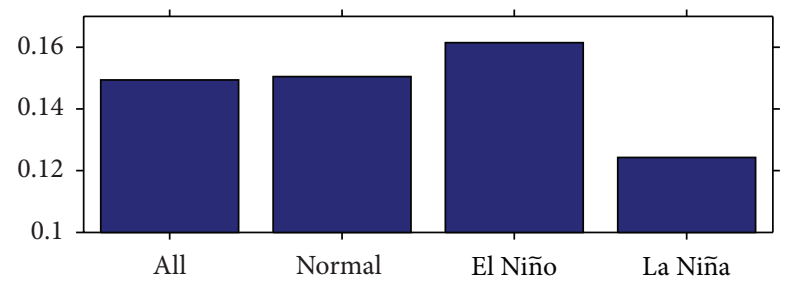

(b) Mean of AOT_F

FIGURE 8: The average AOT over the SCS, (a) coarse mode aerosol, and (b) fine mode aerosol.

from the sea surface may be reduced, and the source of fine particle (AOT_F) generated by the biomass burning from the Indochina Peninsula may be increased.

\section{Conclusions}

In this study, we use coarse mode AOD and fine mode AOD derived from Terra MODIS at $550 \mathrm{~nm}$ from December 2001 to December 2010 to discuss the variation of coarse aerosol (e.g., dust or ocean spray) and fine mode aerosol (e.g., biomass burning or anthropogenic pollution) over the SCS. The variation of AOT_C is in high agreement with the measured coarse aerosol particles of Aeronet observatory. The high-value AOT_C occurs in spring. According to the spatial distribution and the results of this study, China and the Indochina Peninsula are the probable source regions of coarse aerosol particles. Besides, the temporal amplitudes of AOT_C modes show that the average amplitude during the La Niña period is larger.

The significant EOF modes of AOT_F indicate that the high value occurs annually and semiannually. The spatial distribution of each mode and other studies also evidence that the biomass burning, respectively, occurs in the Indochina Peninsula during March and April but occurs from August to October in Sumatra and Borneo. Besides, the results also show that the average amplitude of AOT_F is larger during the El Niño period. It can be concluded that the change of wind direction in the tropical area during the El Niño period may change the distribution of aerosols.

\section{Conflict of Interests}

The authors declare no conflict of interests.

\section{Acknowledgments}

The authors thank Shin-Jie Ho for processing satellite data. This work was supported by the National Science Council of Taiwan under Grants NSC 102-2611-M-019-016 and MOST 103-2611-M-019-006. The MODIS AOD data were from NASA/GSFC LAADS Web: http://ladsweb.nascom.nasa.gov/ data/search.html. The Aeronet data were obtained from NASA/GSFC Aerosol Robotic Network through website at http://aeronet.gsfc.nasa.gov. The Oceanic Niño Index was from NOAA National Weather Service Climate Prediction Center website at http://www.cpc.ncep.noaa.gov/products/ analysis_monitoring/ensostuff/ensoyears.shtml.

\section{References}

[1] K.-M. Lau and M. T. Li, "The monsoon of East Asia and its global associations-a Survey," Bulletin of the American Meteorological Society, vol. 65, no. 2, pp. 114-125, 1984.

[2] C.-R. Ho, Q. Zheng, Y. S. Soong, N.-J. Kuo, and J.-H. Hu, "Seasonal variability of sea surface height in the South China Sea observed with TOPEX/Poseidon altimeter data," Journal of Geophysical Research: Oceans, vol. 105, no. 6, Article ID 2000JC900001, pp. 13981-13990, 2000.

[3] C.-R. Ho, N.-J. Kuo, Q. Zheng, and Y. S. Soong, "Dynamically active areas in the South China Sea detected from TOPEX/POSEIDON satellite altimeter data," Remote Sensing of Environment, vol. 71, no. 3, pp. 320-328, 2000.

[4] N.-J. Kuo, Q. Zheng, and C.-R. Ho, "Response of Vietnam coastal upwelling to the 1997-1998 ENSO event observed by multisensor data," Remote Sensing of Environment, vol. 89, no. 1, pp. 106-115, 2004.

[5] I.-I. Lin, J.-P. Chen, G. T. F. Wong, C.-W. Huang, and C.C. Lien, "Aerosol input to the South China Sea: results from the moderate resolution imaging spectro-radiometer, the quick scatterometer, and the measurements of pollution in the troposphere sensor," Deep-Sea Research Part II: Topical Studies in Oceanography, vol. 54, no. 14-15, pp. 1589-1601, 2007.

[6] T. Holloway, H. Levy II, and G. Carmichael, "Transfer of reactive nitrogen in Asia: development and evaluation of a source-receptor model," Atmospheric Environment, vol. 36, no. 26, pp. 4251-4264, 2002.

[7] S.-C. Tsay, G. Liu, N. Y. Hsu, and W. Sun, "Outbreaks of Asian dust storms: an overview from satellite and surface perspectives," in Recent Progress in Atmospheric Sciences: Applications to the Asia Pacific Region, K. N. Liou and M.-D. Chou, Eds., pp. 373-401, World Scientific Publishing, 2009.

[8] J. Zhao, F. Zhang, Y. Xu et al., "Chemical characteristics of particulate matter during a heavy dust episode in a coastal city, Xiamen, 2010," Aerosol and Air Quality Research, vol. 11, no. 3, pp. 300-309, 2011.

[9] T.-H. Lin, N. C. Hsu, S.-C. Tsay, and S.-J. Huang, "Asian dust weather categorization with satellite and surface observations," International Journal of Remote Sensing, vol. 32, no. 1, pp. 153170, 2011.

[10] S.-H. Wang, S.-C. Tsay, N.-H. Lin et al., "First detailed observations of long-range transported dust over the northern South China Sea," Atmospheric Environment, vol. 45, no. 27, pp. 48044808, 2011.

[11] J. S. Reid, E. J. Hyer, R. S. Johnson et al., "Observing and understanding the Southeast Asian aerosol system by remote 
sensing: an initial review and analysis for the Seven Southeast Asian Studies (7SEAS) program," Atmospheric Research, vol. 122, pp. 403-468, 2013.

[12] N.-H. Lin, S.-C. Tsay, H. B. Maring et al., "An overview of regional experiments on biomass burning aerosols and related pollutants in Southeast Asia: from BASE-ASIA and the Dongsha Experiment to 7-SEAS," Atmospheric Environment, vol. 78, pp. 1-19, 2013.

[13] S. A. Atwood, J. S. Reid, S. M. Kreidenweis et al., "Analysis of source regions for smoke events in Singapore for the $2009 \mathrm{El}$ Nino burning season," Atmospheric Environment, vol. 78, pp. 219-230, 2013.

[14] J. Wang, C. Ge, Z. Yang et al., "Mesoscale modeling of smoke transport over the Southeast Asian Maritime Continent: Interplay of sea breeze, trade wind, typhoon, and topography," Atmospheric Research, vol. 122, pp. 486-503, 2013.

[15] G. R. North, T. L. Bell, R. F. Cahalan, and F. J. Moeng, "Sampling error in the estimation of empirical orthogonal function," Monthly Weather Review, vol. 110, no. 7, pp. 699-706, 1982.

[16] K.-W. Lu, J.-Y. Hu, and X.-Y. Yang, "Spatial patterns in seasonal variability of sea surface wind over the South China Sea and its adjacent ocean," Journal of Tropical Oceanography, vol. 31, pp. 41-47, 2012. 

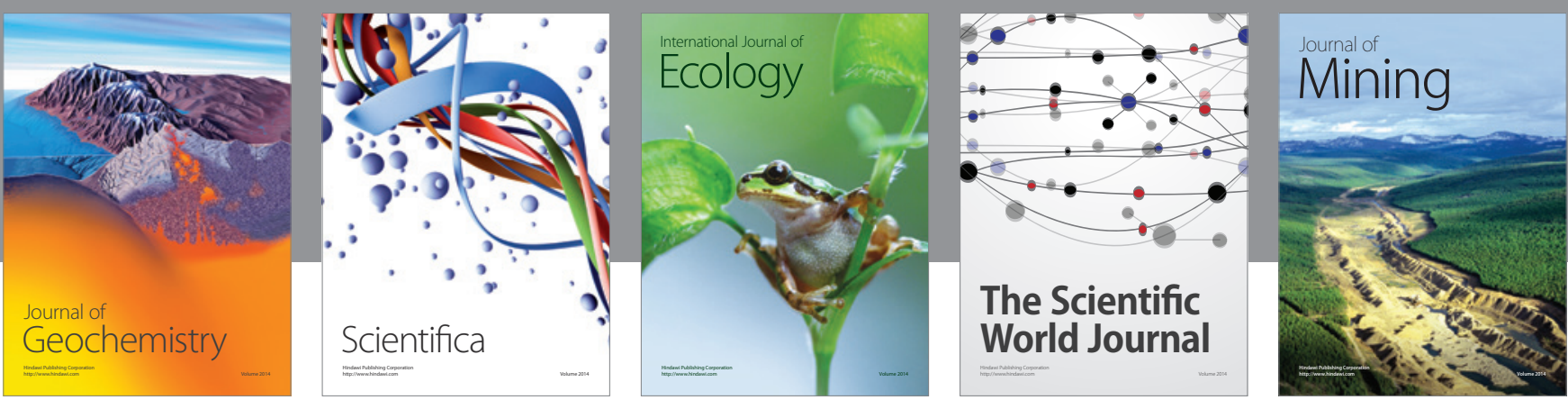

The Scientific World Journal
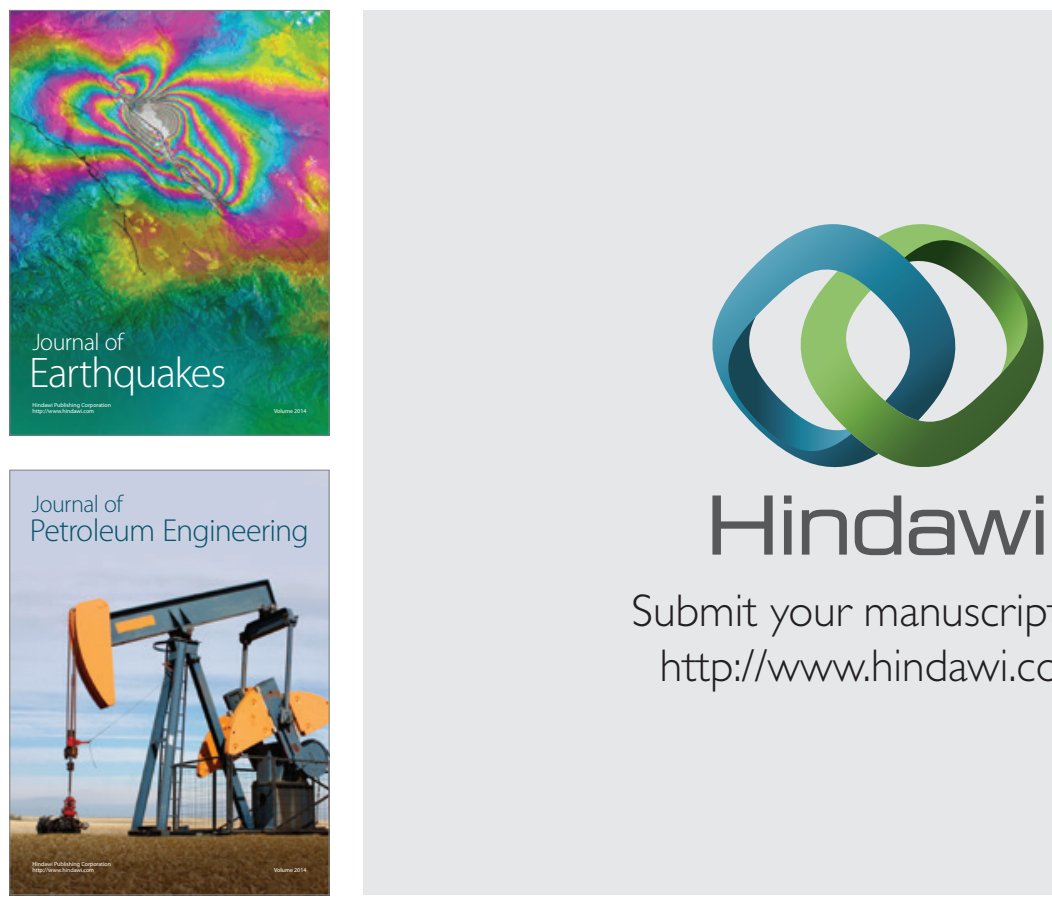

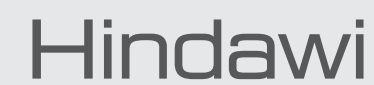

Submit your manuscripts at

http://www.hindawi.com
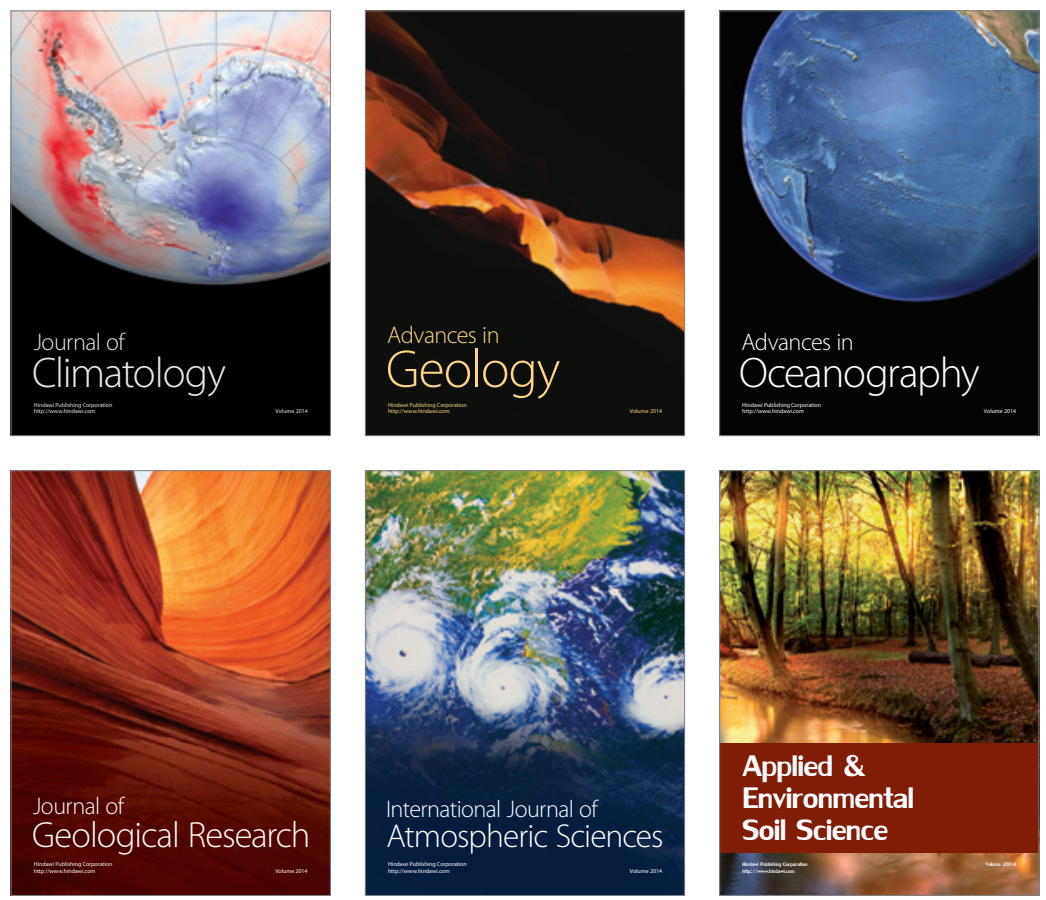
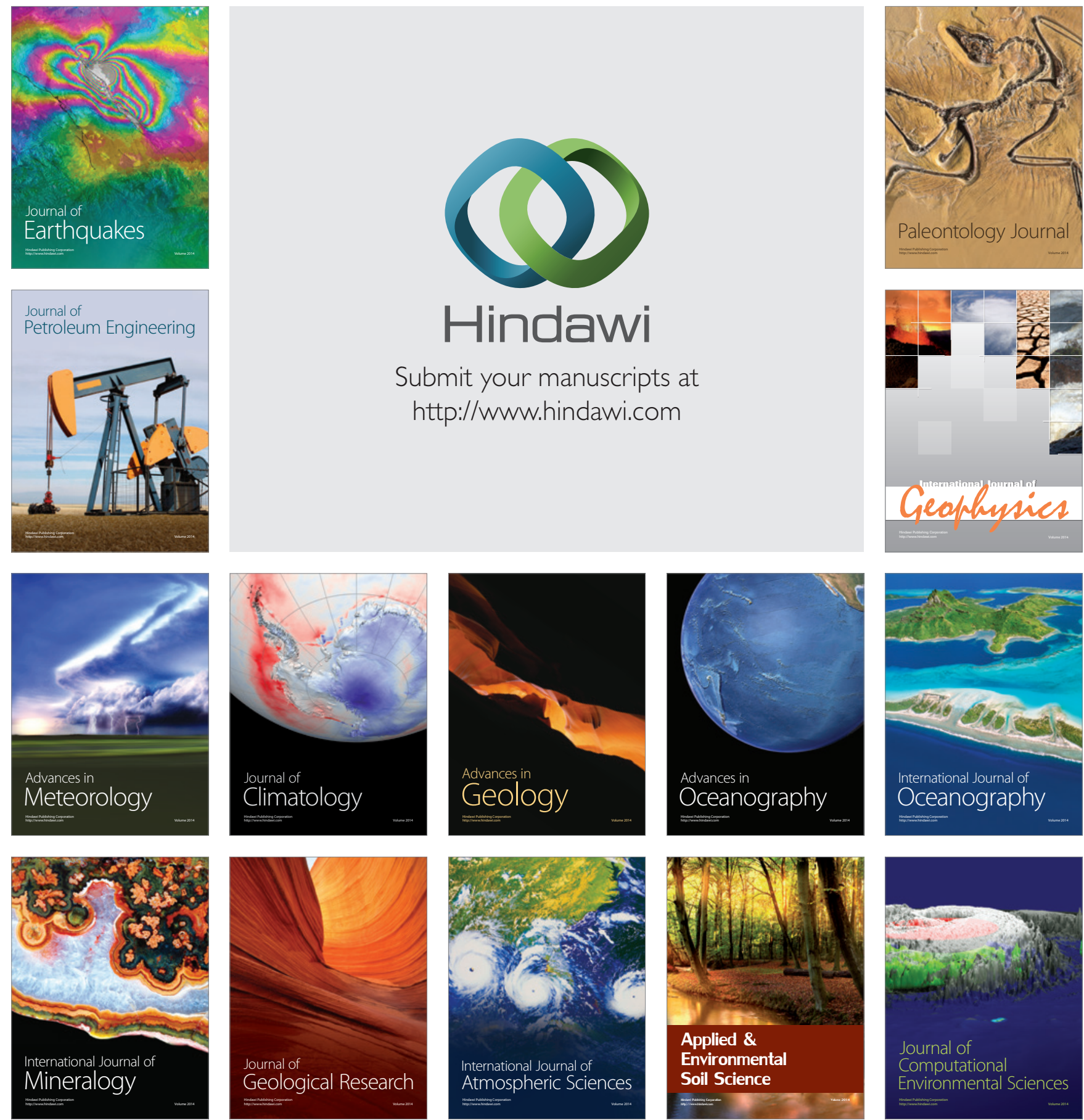